BORGES, T. K. de S; OLIVEIRA, A. S. de; SILVA, N. D. da

Análise da velocidade e direção do vento em Cruz das Almas, Bahia, no período 1973-2001.

DOI: 10.31416/ rsdv.v6i3. 107

\title{
Análise da velocidade e direção do vento em Cruz das Almas, Bahia, no período 1973-2001
}

\author{
Analysis of speed and direction of wind at Cruz das Almas, Bahia, in the 1973-2001 period
}

Tatyana Keyty de Souza Borges, Professora no Instituto Federal de Educação Ciência e Tecnologia do Sertão Pernambucano - Campus Ouricuri/PE, Estrada do Tamboril, S/N, CEP: 56200-000, e-mail: tatyana.borges@ifsertao-pe.edu.br

Aureo Silva de Oliveira, Professor na Universidade Federal do Recôncavo da Bahia (UFRB) Campus Cruz das Almas/BA, Av. Rui Barbosa, n. 710, CEP 44380-000, e-mail: aureo@ufrb.edu.br

Neilon Duarte da Silva, Doutorando em Engenharia Agrícola da UFRB, e-mail: neylon_duart@hotmail.com

\section{RESUMO}

O regime de ventos numa dada região tipicamente baseia-se na análise de séries temporais do vento horizontal em termos de velocidade média e direção predominante. Dessa forma, o trabalho teve como objetivo caracterizar o regime de ventos no município de Cruz das Almas, Bahia (1240’ S, 3906' W, 225 $\mathrm{m}$ anm). Essa análise foi feita a partir de dados diários do INMET de velocidade e direção do vento medido por um anemógrafo universal a $10 \mathrm{~m}$ de altura no período 1973-2001 (29 anos). Em Cruz das Almas, o regime de ventos é fortemente influenciado por centros de alta pressão no Atlântico Sul. A velocidade média diária do vento a $10 \mathrm{~m}$ de altura foi de $2,7 \mathrm{~m} \mathrm{~s}^{-1}$ com 70,4\% das observações concentradas no intervalo de $1,6 \mathrm{~m} \mathrm{~s}^{-1}$ a $3,3 \mathrm{~m} \mathrm{~s}^{-1}$, correspondendo este à classe brisa leve da escala de Beaufort. A direção predominante do vento foi a sudeste (SE), com 88,5\% das observações de todo o período restritas ao intervalo fechado de $90^{\circ}$ (direção leste - E) a $180^{\circ}$ (direção sul - S) da rosa dos ventos. A predominância da direção SE se reproduziu mês a mês (frequência mínima de $35 \%$ em novembro e máxima de $50 \%$ em fevereiro) e também nas estações do ano com frequências de $45 \%, 42 \%$, $48 \%$ e $39 \%$, respectivamente, no verão, outono, inverno e primavera. A direção $\mathrm{S}$ apresentou frequência média de $30 \%$ no outono e inverno tendo esse valor se repetido para ventos de direção $E$ no verão e primavera.

Palavras-chave: Meteorologia, Recôncavo da Bahia, Ventos de superfície, Anemógrafo

\section{ABSTRACT}

Analysis of speed and direction of wind at Cruz das Almas, Bahia, in the 1973-2001 period

The wind regime in a given region is typically based on the analysis of time series of horizontal wind in terms of average velocity and predominant direction. Thus, the objective of this work was to characterize the wind regime in the municipality of Cruz das Almas, Bahia (12 40 'S, 39 $06^{\prime}$ ' W, $225 \mathrm{~m}$ asl). This analysis was based on INMET daily data of wind speed and direction measured by a universal anemograph at $10 \mathrm{~m}$ above ground from 1973 to 2001 (29 years). The National Institute of Meteorology (INMET) database was used as the source of information. In Cruz das Almas, the wind regime is strongly influenced by high-pressure centers in the South Atlantic. The average daily wind velocity at $10 \mathrm{~m}$ in height was found to be $2.7 \mathrm{~m} \mathrm{~s}-1$ with $70.4 \%$ of the observations concentrated in the $1.6 \mathrm{~m} \mathrm{~s}-1$ to $3.3 \mathrm{~m} \mathrm{~s}-1$ interval corresponding to the light breeze class in the Beaufort scale. The predominant direction of the wind was southeast (SE), with $88.5 \%$ of the observations of the entire period restricted to the closed interval from $90^{\circ}$ (east - E direction) to 180 o (south - S direction) of the wind rose. The predominance of the SE direction was reproduced month-by-month (minimum frequency of $35 \%$ in November and maximum of $50 \%$ in February) and season-by-season with frequencies of $45 \%, 42 \%, 48 \%$ and $39 \%$, respectively, in the summer, autumn, winter and spring. The S direction presented a mean frequency of $30 \%$ in autumn and winter, having this value repeated for easterly winds in summer and spring.

Keywords: Meteorology, Recôncavo da Bahia, Surface winds, Anemograph 
BORGES, T. K. de S; OLIVEIRA, A. S. de; SILVA, N. D. da

Análise da velocidade e direção do vento em Cruz das Almas, Bahia, no período 1973-2001.

\section{Introdução}

Inúmeros processos na interface superfície-atmosfera são influenciados pelo vento. Estudos de dispersão de poluentes e transporte de calor e massa via fluxos turbulentos demandam medições do vento (Allen et al., 1998; Oliveira et al., 2012). É crescente no mundo atual o aproveitamento da força do vento para geração de energia elétrica (Martins et al., 2008). No setor agropecuário, cortinas vivas (quebra ventos) minimizam os efeitos danosos do vento sobre culturas agrícolas. Outras práticas devem igualmente considerar a influência do vento como a construção e orientação de galpões, aplicação de pesticidas, evaporação de reservatórios, irrigação por aspersão entre outras (Abi Saab, 2004; Jensen \& Allen, 2016; Borges, 2017).

0 vento é originado de diferenças de pressão atmosférica, resultantes de aquecimento diferencial da superfície terrestre (Stull, 2017). Na atmosfera inferior, o vento sofre a influência de fatores locais como a fricção com a superfície e a configuração do terreno (orografia) (Alves \& Silva, 2011; Costa \& Lyra, 2012). Na atmosfera superior, acima da camada limite atmosférica, a direção do vento é determinada pelo equilíbrio entre as forças de Coriolis devido à rotação da Terra e a do gradiente horizontal de pressão (Lutgens \& Tarbuck, 2013).

Diferente de outras variáveis meteorológicas o vento é uma grandeza vetorial, com direção e módulo. 0 módulo do vetor velocidade é nulo próximo da superfície, devido à fricção, e aumenta logaritmicamente com a altura em condições de atmosfera neutra (Stull, 2017). O vento é tipicamente turbulento, especialmente quando o ar flui no limite inferior da Troposfera (VarejãoSilva, 2001). A direção do vento é de onde o vento sopra. A rosa dos ventos é uma representação gráfica da direção do vento segundo os pontos cardeais principais e colaterais. Assim, vento oeste tem direção de $270 \mathrm{o}$ em coordenadas polares, ângulo este denominado azimute, medido no sentido horário a partir do norte geográfico, onde o azimute é zero. (Varejão-Silva, 2001; Stull, 2017). A força do vento depende da velocidade, sendo caracterizada com base na escala de Beaufort, originalmente concebida para fins de navegação marítima (Hasse, 2003).

0 regime local de ventos é descrito com base em séries históricas de dados de velocidade horizontal e direção. Denomina-se direção predominante do vento a que ocorre em maior frequência. Em Mossoró/RN, por exemplo, Morais et al. (2014) verificaram com dados de 2000 a 2012 que a direção predominante do vento na maioria dos meses do ano ficou entre leste (90o) e sudeste (1350). A velocidade média foi de $3,3 \mathrm{~m} \mathrm{~s}-1$ a $10 \mathrm{~m}$ de altura e 2,3 m s-1 a $2 \mathrm{~m}$ de altura, com valores máximos de 13,0 m s-1 (10 m) e 9,4 m s-1 (2 m). No litoral nordeste do Pará (município de Salinópolis) a máxima velocidade do vento observada por Pontes et al (2018) foi de 3,8 m s-1 com ventos predominantemente vindos da direção nordeste (45o).

O presente estudo teve por objetivo caracterizar o regime de ventos no município de Cruz das Almas, Bahia, ao apresentar a evolução da velocidade média anual no período bem como a distribuição sazonal da direção do vento. 
BORGES, T. K. de S; OLIVEIRA, A. S. de; SILVA, N. D. da

Análise da velocidade e direção do vento em Cruz das Almas, Bahia, no período 1973-2001.

\section{Material e métodos}

Dados meteorológicos da estação A406, integrante da rede oficial do Instituto Nacional de Meteorologia (INMET) foram utilizados neste estudo. A referida estação localiza-se no Campo Experimental da Embrapa Mandioca e Fruticultura em Cruz das Almas, Bahia (12 40' S; 39० 06' W; $225 \mathrm{~m}$ anm). Por se tratar de uma localidade relativamente próxima à costa brasileira (não mais do que $70 \mathrm{~km}$ em linha reta) a influência do oceano é relevante e o clima local é de transição entre os tipos Af e Am (Alvares et al., 2014) na tipologia climática de Köppen. Médias anuais de temperatura do ar e umidade relativa são $24{ }^{\circ} \mathrm{C}$ e $70 \%$, respectivamente. A precipitação anual média é de 1100 $\mathrm{mm}$.

Os dados de vento (direção e velocidade) utilizados neste estudo, representando períodos de 24 horas no intervalo de 1973 a 2001 (29 anos), foram coletados por um anemógrafo universal com sensores de direção e velocidade posicionados a $10 \mathrm{~m}$ de altura. Assim, para cada dia do período tinha-se uma direção do vento e um valor de velocidade média. Na série de dados, a direção do vento era apresentada de forma qualitativa em oito classes correspondentes aos pontos cardeais da rosa dos ventos, agrupados em principais ( $\mathrm{N}$ - norte, $\mathrm{S}$ - sul, E - leste e W - oeste) e pontos colaterais (NE - nordeste, SE - sudeste, SW - sudoeste e NO - noroeste).

A qualidade dos dados na série foi conferida checando-se a ocorrência de falhas bem como a de valores discrepantes. De um total de 10.592 observações possíveis em 29 anos, 10.377 (98\%) foram validadas para direção do vento, tendo-se observado dados ausentes no ano de 1974. Falhas na série não foram identificadas para velocidade do vento. No entanto, alguns valores muito altos (>10 m s-1) foram considerados discrepantes em se tratando de média diária. Erro de digitação quando da transferência dos dados do boletim meteorológico para a planilha pode ser a causa provável. Tais valores discrepantes foram ajustados após comparação com outros na vizinhança dentro da série.

A análise da distribuição temporal da velocidade do vento a $10 \mathrm{~m}$ de altura foi feita em escala anual, estacional e mensal. Através da escala de Beaufort (Tabela 1), o regime de vento foi associado a doze possíveis classes de intensidade (WMO, 2008).

Tabela 1. Escala de Beaufort para classificação da força em função da velocidade do ar. Número da escala

\begin{tabular}{ccc}
\hline $\begin{array}{c}\text { Número da } \\
\text { escala }\end{array}$ & Descrição & $\begin{array}{r}\text { Velocidade do vento (m/s) } \\
\text { equivalente a uma altura padrão de } \\
10 \text { m acima da superfície do solo }\end{array}$ \\
\hline 0 & Calmo & $0-0,2$ \\
1 & Aragem & $0,3-1,5$ \\
2 & Brisa leve & $1,6-3,3$ \\
3 & Brisa fraca & $3,4-5,4$ \\
4 & Brisa moderada & $5,5-7,9$ \\
5 & Brisa fresca & $8,0-10,7$ \\
6 & Brisa forte & $10,8-13,8$ \\
7 & Ventania fraca & $13,9-17,1$
\end{tabular}


BORGES, T. K. de S; OLIVEIRA, A. S. de; SILVA, N. D. da

Análise da velocidade e direção do vento em Cruz das Almas, Bahia, no período 1973-2001.

\begin{tabular}{ccc}
8 & Ventania & $17,2-20,7$ \\
9 & Ventania forte & $2,8-24,4$ \\
10 & Tempestade & $24,5-28,4$ \\
11 & Tempestade violenta & $28,5-32,6$ \\
12 & Furacão & $\geq 32,7$ \\
\hline
\end{tabular}

Fonte: WMO, 2008.

A direção predominante do vento foi caracterizada via análise de frequências relativas apresentadas na forma de diagramas polares (rosa dos ventos) (Varejão-Silva, 2001). Nestes diagramas, as direções principais e colaterais são apresentadas em intervalos de $45^{\circ}$ a partir da direção norte, para a qual o ângulo é zero. A frequência relativa de uma dada direção foi calculada conforme a Eq. (1).

$$
F=\frac{n}{N} \cdot 100
$$

em que $\mathrm{F}$ = frequência do vento horizontal numa dada direção, $\mathrm{n}$ = número de observações naquela direção e $\mathrm{N}$ = número total de observações no período.

\section{Resultados e discussão}

\section{Aspectos da velocidade do vento}

A Figura 1 mostra a distribuição da velocidade média diária anual do vento a $10 \mathrm{~m}$ de altura de 1973 a 2001. Nessa escala anual, a velocidade média diária oscilou de 1,7 $\mathrm{m} \mathrm{s}^{-1}$ em 1992 a 3,7 m $\mathrm{s}^{-1}$ em 1996 e 1998, com média de 2,7 $\mathrm{m} \mathrm{s}^{-1}$ e amplitude de 2,0 $\mathrm{m} \mathrm{s}^{-1}$. No longo prazo, o vento manteve-se estável de 1973 a 1990 com ligeiro decréscimo nos dois anos seguintes (1991 e 1992). A partir de 1993 até 1998 a série de dados de dados de velocidade do vento revelou tendência de crescimento voltando a se estabilizar no restante do período (1999 a 2001).

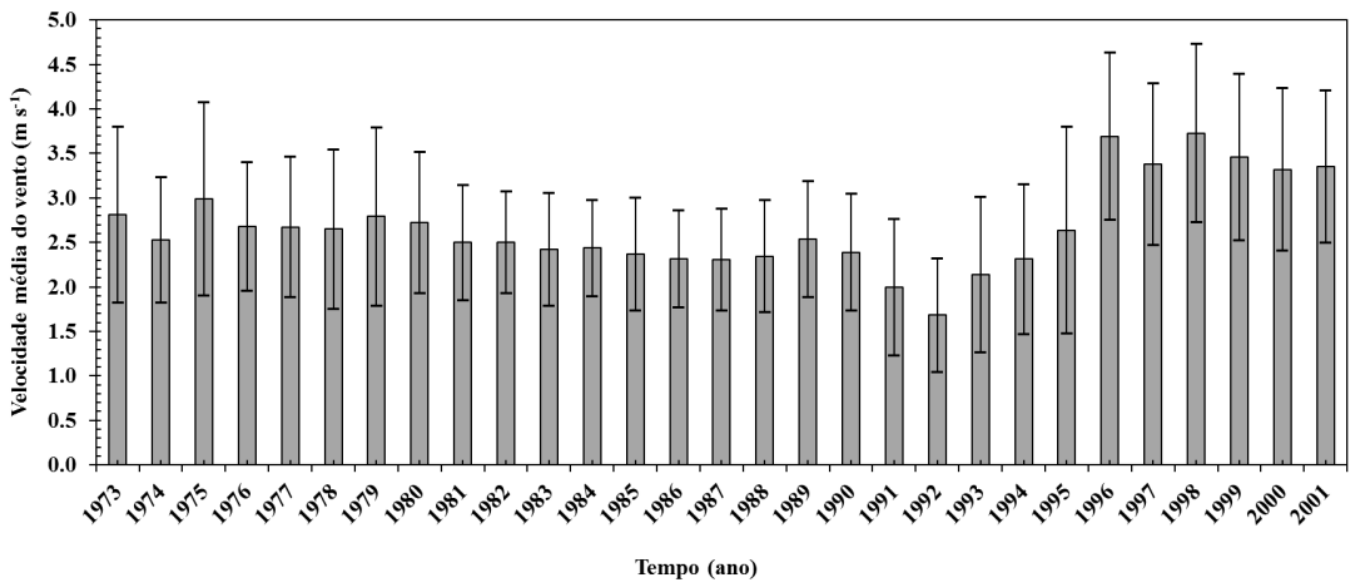

Figura 1. Distribuição da velocidade média diária anual do vento a $10 \mathrm{~m}$ de altura em Cruz das Almas, Bahia, no período de 1973 a 2001. 
BORGES, T. K. de S; OLIVEIRA, A. S. de; SILVA, N. D. da

Análise da velocidade e direção do vento em Cruz das Almas, Bahia, no período 1973-2001.

Análise de tendência temporal da velocidade do vento tem sido objeto de estudo em várias partes do mundo (Dadaser-Celik \& Cengiz, 2014; Torralba et al., 2017) em conexão com cenários de mudanças climáticas. Para cada ano do período, a Figura 1 também mostra o intervalo de variação da velocidade do vento com desvio mínimo $\left( \pm 0,5 \mathrm{~m} \mathrm{~s}^{-1}\right)$ observado em 1984 e 1985 e desvio máximo $\left( \pm 1,2 \mathrm{~m} \mathrm{~s}^{-1}\right)$ em 1995 .

Após agrupamento dos dados por estação do ano, verificou-se que a velocidade média pouco diferiu entre o inverno, primavera, verão e outono. A menor média $\left(2,5 \mathrm{~m} \mathrm{~s}^{-1}\right)$ foi observada no outono e a maior $\left(2,9 \mathrm{~m} \mathrm{~s}^{-1}\right)$ na primavera. Este regime estacional do vento observado em Cruz das Almas é semelhante ao reportado por Silva et al. (1997) em Pelotas, Rio Grande do Sul, onde os autores também observaram a ocorrência de ventos mais intensos $\left(4,0 \mathrm{~m} \mathrm{~s}^{-1}\right)$ na primavera e menos intensos $\left(2,7 \mathrm{~m} \mathrm{~s}^{-1}\right)$ no outono, com média de $3,3 \mathrm{~m} \mathrm{~s}^{-1}$ tanto no inverno quanto no verão. $\mathrm{Na}$ localidade do presente estudo, as velocidade máximas diárias observadas foram da ordem de 9,7 $\mathrm{m} / \mathrm{s}$ (inverno), seguida de $9,0 \mathrm{~m} / \mathrm{s}, 8,2 \mathrm{~m} / \mathrm{s}$ e $7,3 \mathrm{~m} / \mathrm{s}$ nas estações da primavera, verão e outono, respectivamente. Em escala mensal, a velocidade média do vento em Cruz das Almas variou de 2,5 $\mathrm{m} \mathrm{s}^{-1}$ em abril, maio e junho a $2,9 \mathrm{~m} \mathrm{~s}^{-1}$ em outubro.

A distribuição de frequência da velocidade do vento através das classes da escala de Beaufort (Tabela 1) é apresentada na Figura 2. As observações do período de 29 anos se dividiram principalmente entre classes de intensidade 1,2 e 3 . Na classe 1 (aragem - 0,3 a 1,5 m s $\mathrm{m}^{-1}$ ) o percentual observado foi em torno de $10 \%$, seguido de $70,4 \%$ e $18 \%$ para as classes de intensidade 2 (brisa leve - 1,6 a 3,3 $\mathrm{m} \mathrm{s}^{-1}$ ) e 3 (brisa fraca - 3,4 a 5,4 $\mathrm{m} \mathrm{s}^{-1}$ ). A classe 2 contém o vento médio diário em Cruz das Almas, no período avaliado, sendo portanto um vento predominantemente do tipo brisa leve

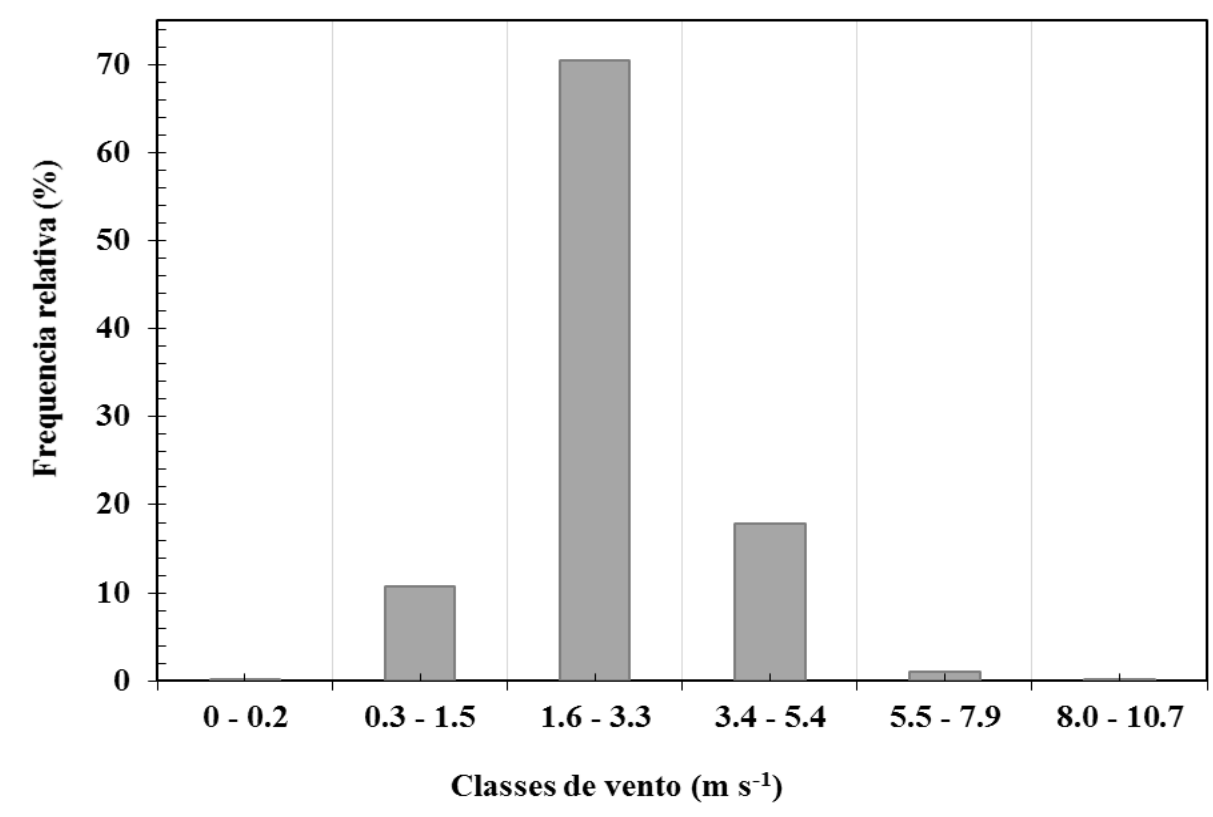

Figura 2. Enquadramento da intensidade do vento a $10 \mathrm{~m}$ de altura nas classes da escala de Beaufort, no período de 1973 a 2001, em Cruz das Almas, Bahia. 
BORGES, T. K. de S; OLIVEIRA, A. S. de; SILVA, N. D. da

Análise da velocidade e direção do vento em Cruz das Almas, Bahia, no período 1973-2001.

Aspectos da direção do vento

A Figura 3 mostra a distribuição da frequência relativa da direção do vento em Cruz das Almas, Bahia, no período de 1973-2001. Os valores apresentados na Figura 3A correspondem à média aritmética de doze frequências médias mensais (FMM), sendo esta a média aritmética de 29 valores de frequência de direção do vento para um dado mês. Observa-se que de 1973 a 2001, o vento soprou predominantemente do quadrante leste-sul (88,5\% das observações), com a seguinte distribuição: direção SE - 43,6\%, direção E - 23,1\% e direção S - 21,8\%. Nas demais direções foi praticamente inexistente a ocorrência de ventos $(\leq 1 \%)$ exceto na direção NE onde se verificou frequência média de 6,6\%.
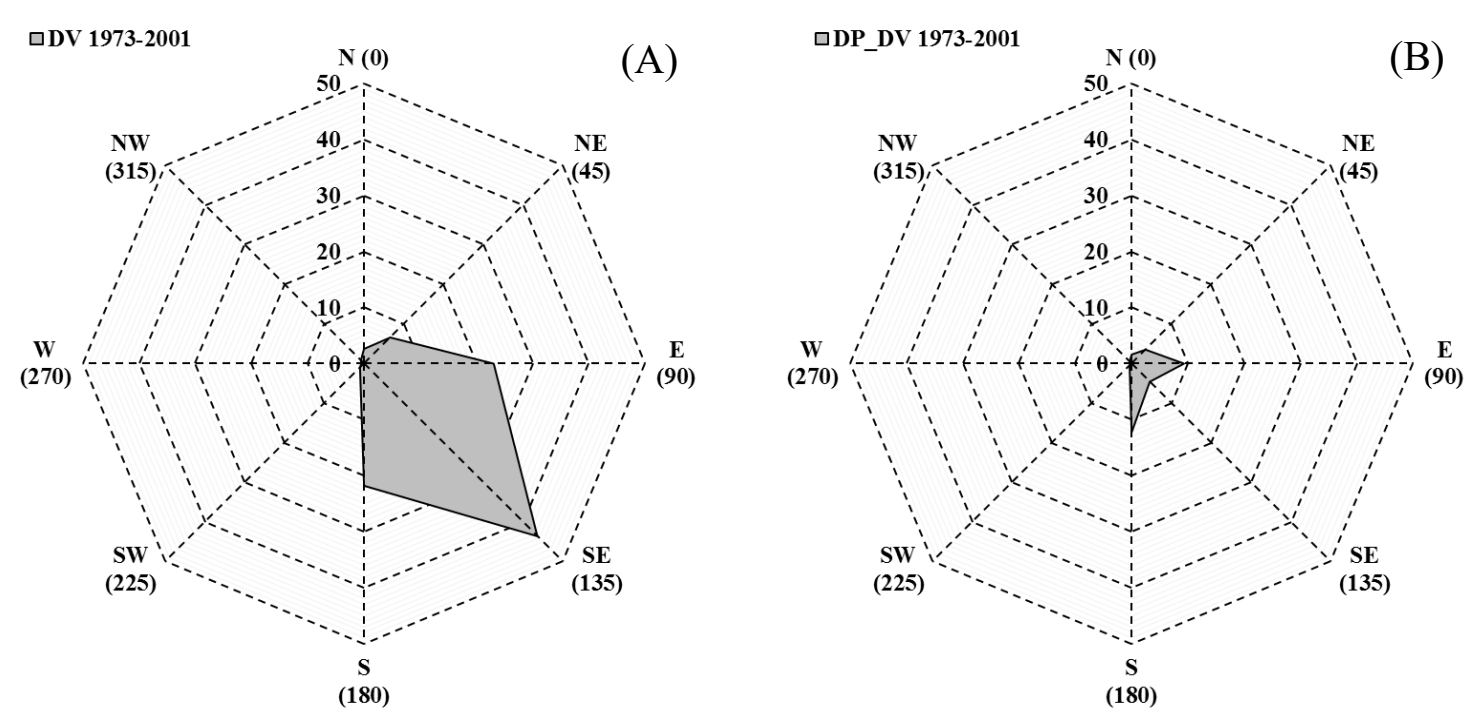

Figura 3. Frequência relativa (\%) da direção do vento (DV) a $10 \mathrm{~m}$ de altura em Cruz das Almas, BA, no período de 1973-2001 (A) e em (B) o correspondente desvio padrão (DP).

A Figura 3B mostra a dispersão da FMM da direção do vento. A maior dispersão verificou-se na direção S, tendo a FMM oscilado de 6,90\% em dezembro a 42,02\% em junho. A direção SE além de ser a predominante é a de frequência mais estável no quadrante leste-sul (4,57\% de desvio padrão). O desvio padrão das FMM na direção E foi de 9,30\%.

Esta predominância de ventos no setor leste-sul em Cruz das Almas, Bahia, explica-se, como já mencionado, pela sua proximidade com o oceano. Ventos sopram do Atlântico, a leste da localidade, sendo inclusive essas correntes de ar responsáveis pela ocorrência de chuvas (D’Angiolella et al., 2002), especialmente nos meses de abril a julho (outono-inverno), devido ao surgimento de centros de alta pressão (ciclones) no Atlântico Sul que giram no sentido anti-horário empurrando o ar para o continente.

As Figuras 4A e 4B ilustram a distribuição da FMM mês a mês de janeiro a junho (Figura 4A) e de julho a dezembro (Figura 4B). Como já mencionado, cada valor de FMM num dado mês para uma dada direção é a média aritmética de 29 valores, cobrindo o período de 1973 a 2001. 
$\square \mathbf{J A N}$

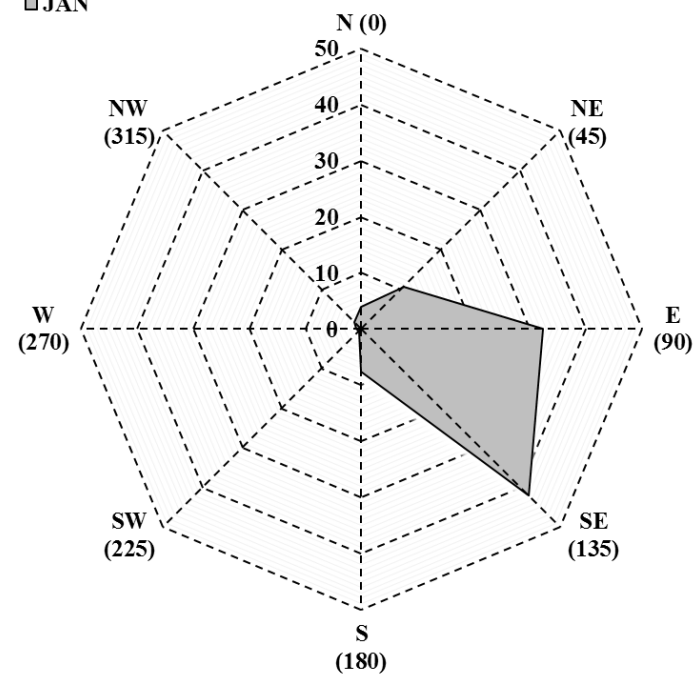

口MAR

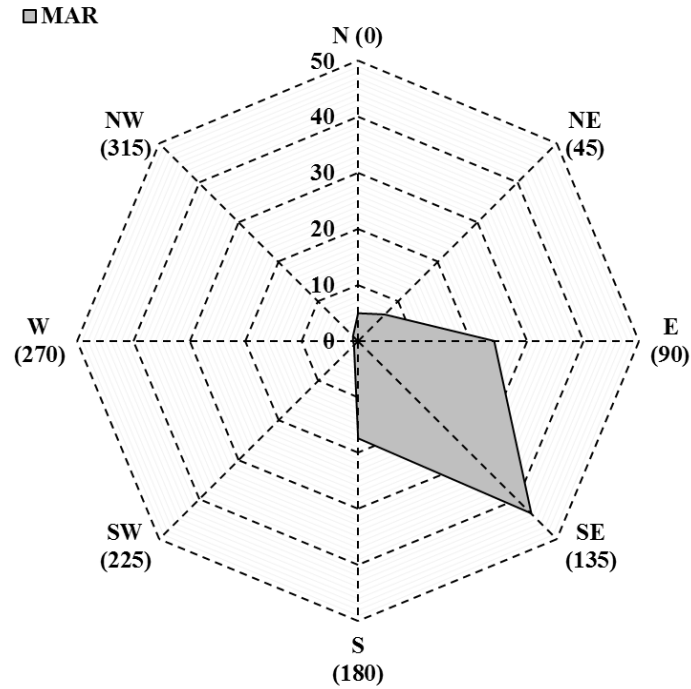

$\square$ MAI

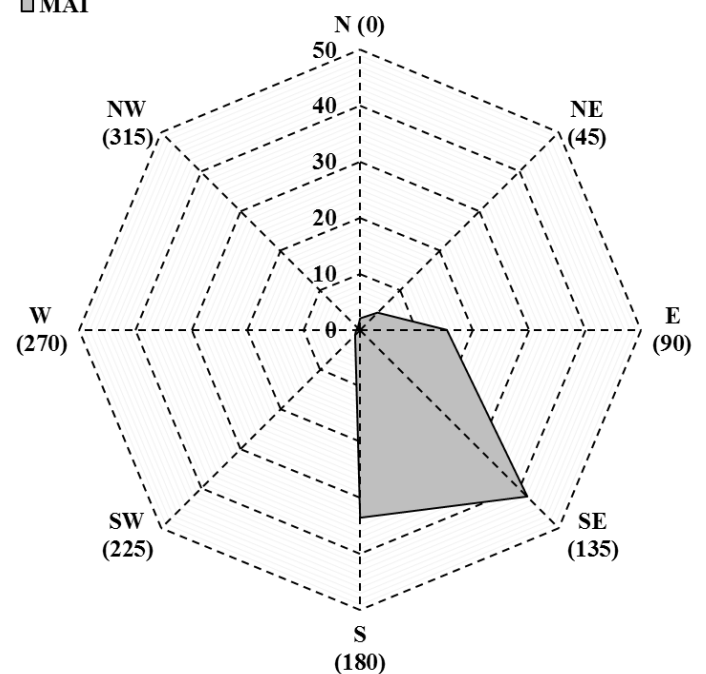

$\square$ FEV
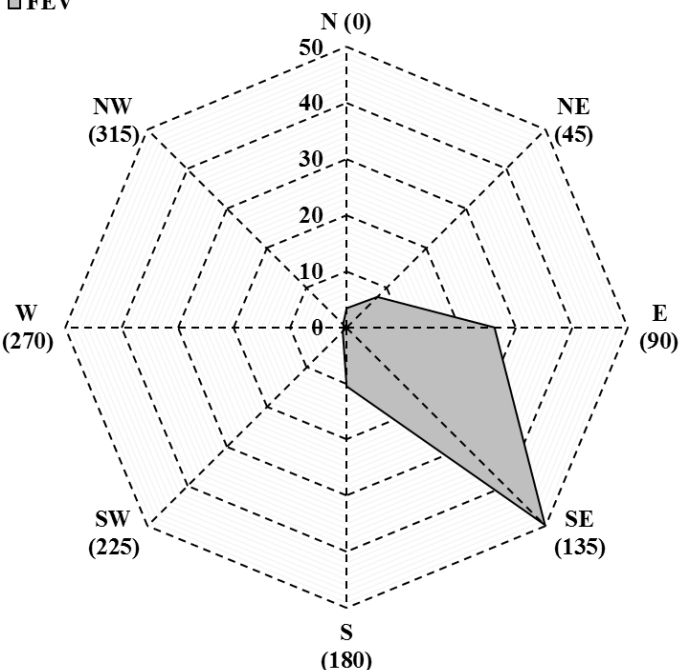

$\square$ ABR

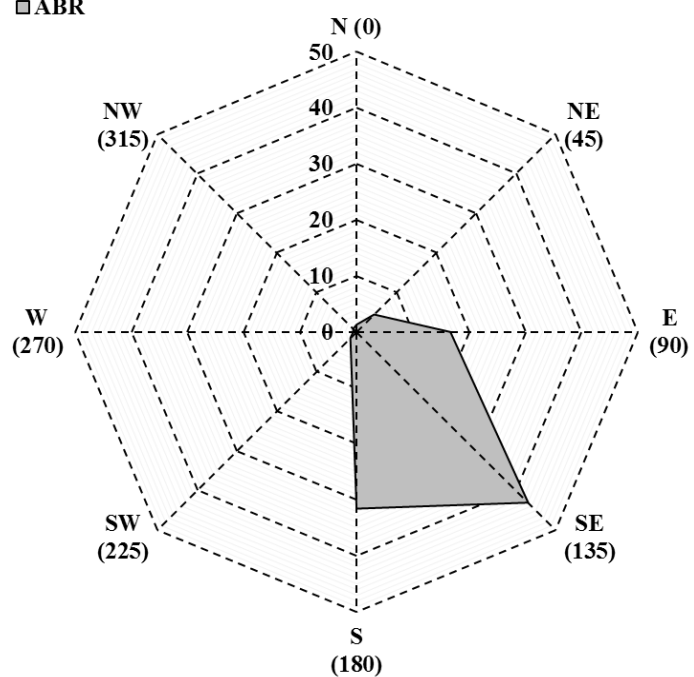

$\square$ JUN

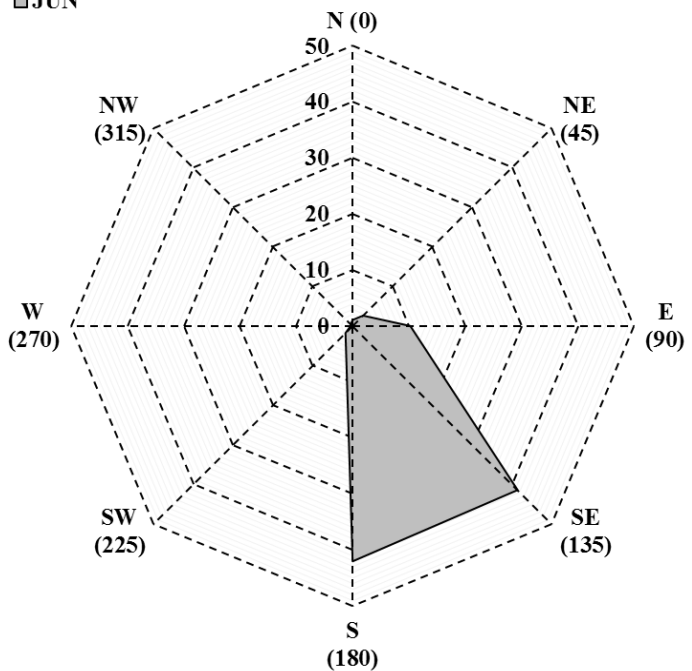

Figura 4A. Frequência relativa (\%) da direção predominante do vento a $10 \mathrm{~m}$ de altura nos meses do primeiro semestre do ano, em Cruz das Almas, BA, de 1973 a 2001. 
BORGES, T. K. de S; OLIVEIRA, A. S. de; SILVA, N. D. da

Análise da velocidade e direção do vento em Cruz das Almas, Bahia, no período 1973-2001.

Em todos os meses do ano a direção do vento é quase que exclusivamente restrita ao quadrante leste-sul ( $2^{\circ}$ quadrante no sentido horário). Neste quadrante, é evidente o predomínio da direção SE em relação às direções S e E. Com exceção de novembro e dezembro, o vento de direção SE apresentou frequência superior a 40\%, com máximo de $50 \%$ nos meses de fevereiro, agosto e setembro. Porém, de abril a julho acentuou-se a frequência de ventos de direção $S$, culminando com $42 \%$ (a mesma para direção SE) no mês de junho. Em sete meses do ano, ventos de direção $E$ se apresentaram com frequências superiores a $20 \%$, alcançando máximo de $35 \%$ em novembro e dezembro. Também em Mossoró, RN, a direção SE foi a predominante na maior parte do ano (março a setembro) segundo Morais et al. (2014).

$\square$ JUL

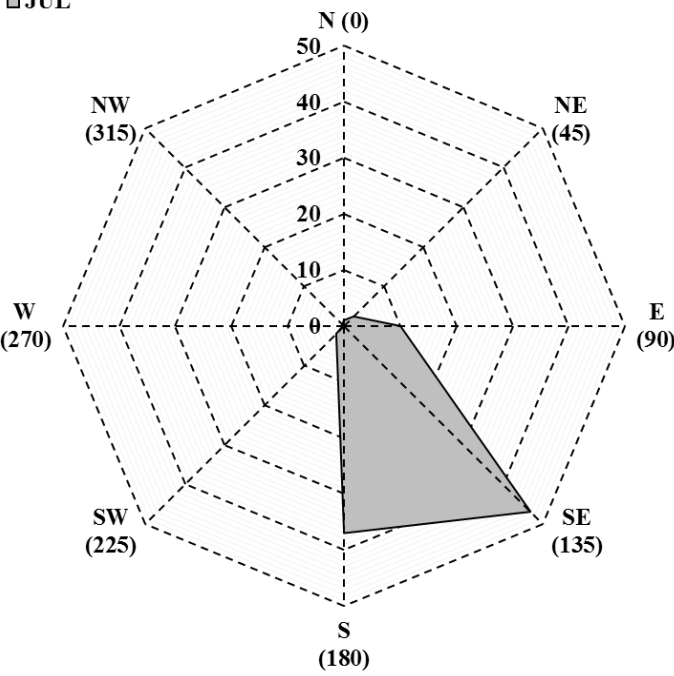

口SET

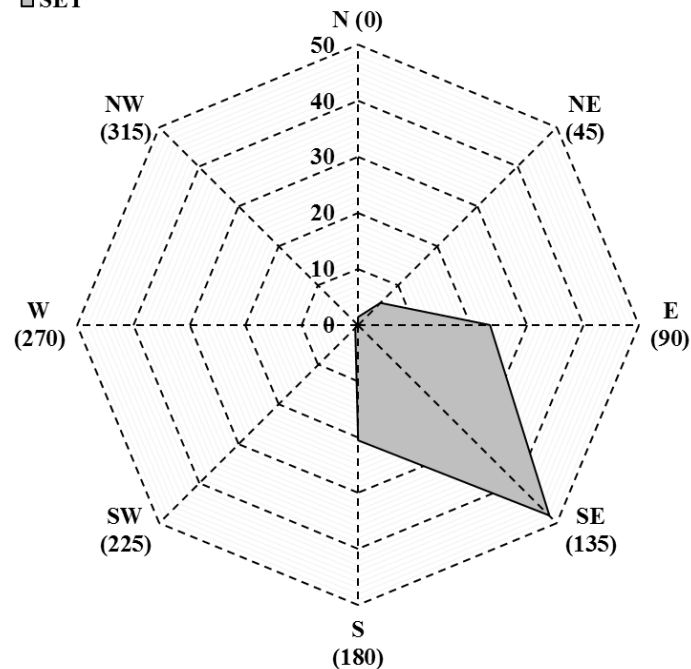

$\square$ AGO

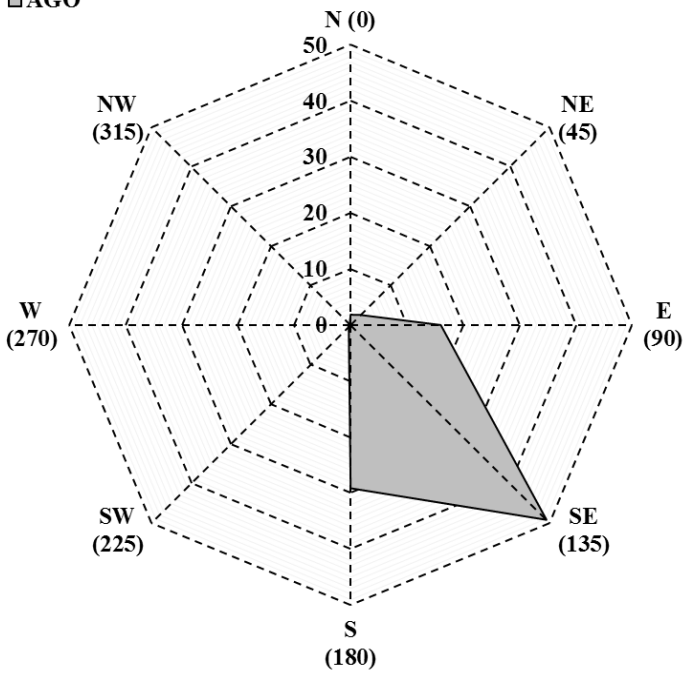

口OUT

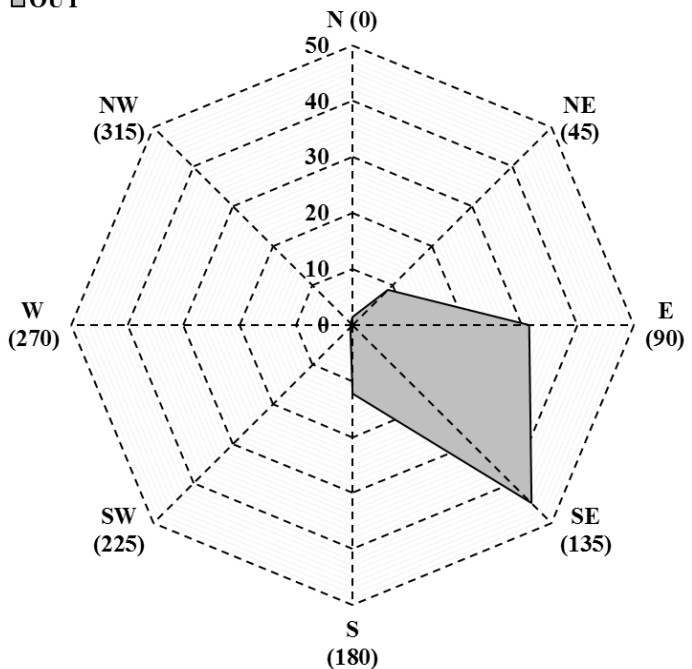



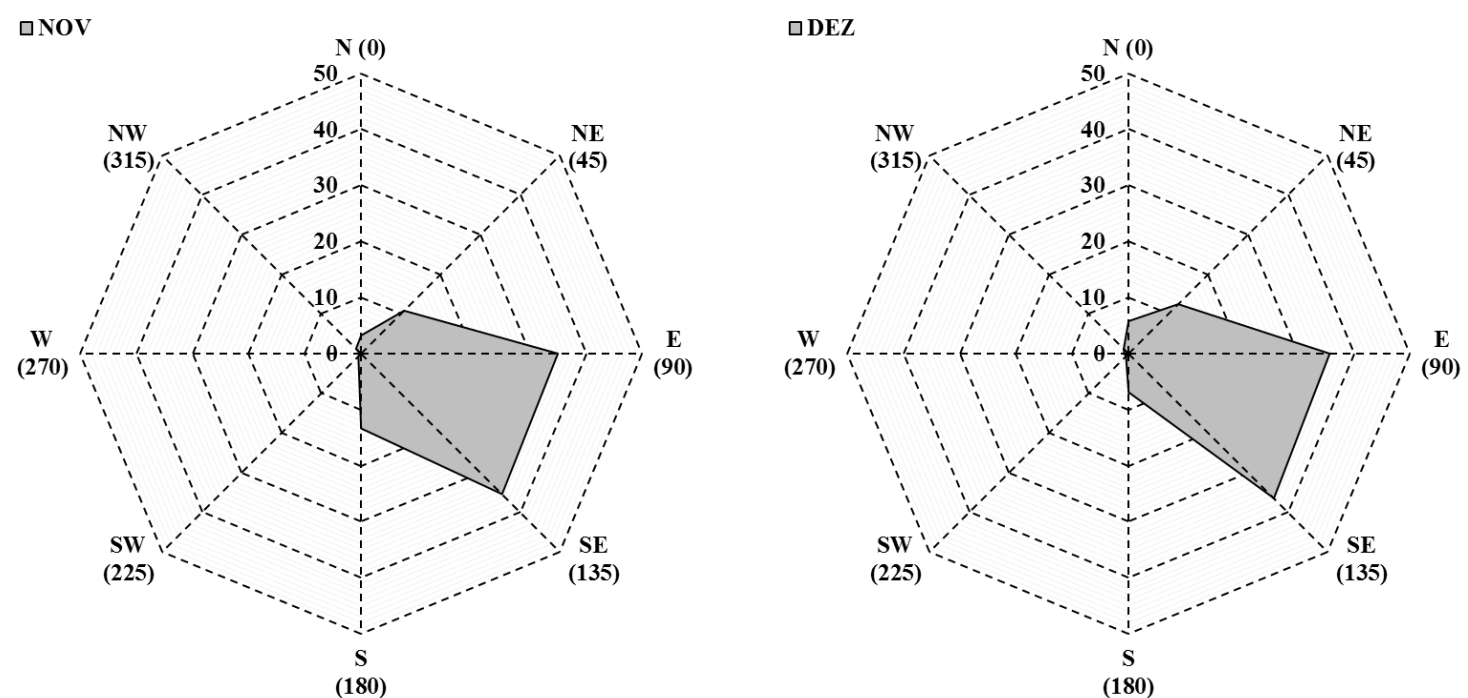

Figura 4B. Frequência relativa (\%) da direção predominante do vento a $10 \mathrm{~m}$ de altura nos meses do segundo semestre do ano, em Cruz das Almas, BA, de 1973 a 2001.

Ventos de direção NE se apresentaram com frequências ligeiramente superiores a $10 \%$ de novembro a janeiro e inferiores a $10 \%$ nos demais meses. 0 registro de ventos com direções maiores que $180^{\circ}$ e menores que $45^{\circ}$ ( $3^{\circ}$ e $4^{\circ}$ quadrantes e metade do $1^{\circ}$ quadrante) foi praticamente zero. Portanto, mês a mês, os ventos no período analisado sopraram predominantemente de direções contidas no intervalo fechado de $90^{\circ}$ a $180^{\circ}$. Segundo Costa \& Lyra (2012), a ausência de variabilidade na direção é considerado um fator positivo para fins de aproveitamento eólico, pois tende a diminuir o tempo de ociosidade das turbinas eólicas quando devidamente orientadas.

Os dados de direção do vento no período de 1973 a 2001 também foram agrupados segundo as estações do ano, ou seja, verão, outono, inverno e primavera. A Figura 5 evidencia a predominância de ventos de direção SE em todas as quatro estações, especialmente no inverno e verão (48\% e 45\%, respectivamente). Munhoz \& Garcia (2008), encontraram predominância de vento SE, com exceção do período de verão (dezembro, janeiro e fevereiro), em que também predominou ventos (NW), em Ituverava/SP.

No outono e no inverno (Figura 5), ocorreu também razoável percentual de ventos de direção S (33\% e 31\%, respectivamente), enquanto que a segunda direção com a maior frequência foi a $E$, com $29 \%$ no verão e $33 \%$ na primavera. A maior frequência de ventos de direção E-SE-S em Cruz das Almas, no Recôncavo da Bahia, possivelmente está associada aos alísios de SE no Hemisfério Sul. Munhoz \& Garcia (2008) explicam que os alísios estão associados ao sistema meteorológico Centro de Alta Pressão do Atlântico e que a posição e a intensidade desse centro anticiclone são alteradas sazonalmente, modificando consequentemente o padrão dos ventos. 

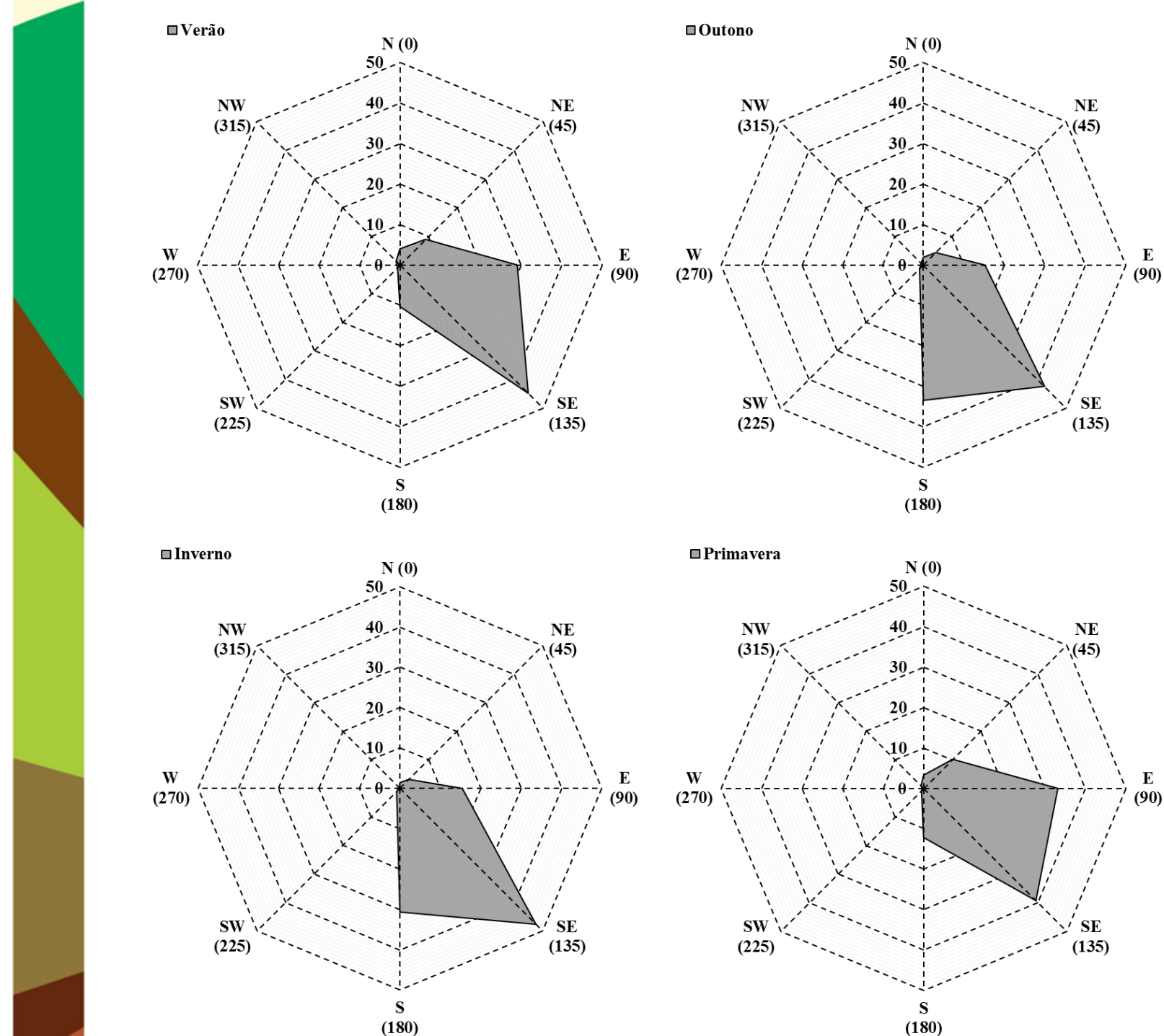

Figura 5. Frequência relativa (\%) da direção predominante do vento horizontal a $10 \mathrm{~m}$ de altura nas quatro estações do ano, em Cruz das Almas, BA, de 1973 a 2001.

Silva et al. (2002) avaliaram o potencial eólico para alguns municípios dos estados da Região Nordeste do Brasil e verificaram que a Bahia é o estado com a maior variabilidade na direção predominante do vento. Os autores relacionam essa variabilidade à grande dimensão territorial da Bahia e também ao fato de o estado estar submetido a ação de diferentes sistemas meteorológicos, tais como: sistemas frontais, alta semipermanente do Atlântico sul, ondas de leste, dentre outros. Nesse estudo de Silva et al. (2002) foi avaliado o regime de ventos em 22 localidades da Bahia, porém Cruz das Almas não estava incluída. 
BORGES, T. K. de S; OLIVEIRA, A. S. de; SILVA, N. D. da

Análise da velocidade e direção do vento em Cruz das Almas, Bahia, no período 1973-2001.

\section{Conclusões}

A velocidade média diária do vento a $10 \mathrm{~m}$ de altura no município de Cruz das Almas, região do Recôncavo da Bahia, foi de 2,7 $\mathrm{m} \mathrm{s}^{-1}$ no período de 1973 a 2001 (29 anos), com 70,4\% dos dados concentrados no intervalo de 1,6 a 3,3 $\mathrm{m} \mathrm{s}^{-1}$, correspondente à classe brisa leve na escala de Beaufort. A direção predominante do vento foi sudeste (SE), com $88,5 \%$ das observações restritas ao intervalo fechado de $90^{\circ}$ (direção E) a $180^{\circ}$ (direção S) da rosa dos ventos. A predominância da direção SE se reproduziu mês a mês (frequência mínima de $35 \%$ em novembro e máxima de $50 \%$ em fevereiro) e também nas estações do ano com frequências de $45 \%$ (verão), $42 \%$ (outono), $48 \%$ (inverno) e 39\% (primavera). A direção S apresentou frequência média de $30 \%$ no outono e inverno repetindo esse valor para a direção $\mathrm{E}$ no verão e primavera.

\section{Referências}

ABI SAAB, O.J.G. Indicador de velocidade do vento. Semina: Ciências Agrárias, v. 25, n. 1, p. 21-26, 2004.

ALLEN, R.G.; PEREIRA, L.S.; RAES, D.; SMITH, M. Crop Evapotranspiration: guidelines for computing crop water requirements. Irrigation and Drainage Paper 56, FAO, Rome, 1998. 297p.

ALVARES, C.A.; STAPE, J.L.; SENTELHAS, P.C.; GONÇALVES, J.L. de M.; SPAROVEK, G. Koppen's climate classification map for Brazil. Meteorologische Zeitschrift, v. 22, n. 6, p. 711-728, 2014.

ALVES, E.D.L.; SILVA, S.T. Direção e velocidade do vento em uma floresta de transição AmazôniaCerrado no norte de Mato Grosso, Brasil. Boletim Goiano de Geografia, v. 31, n. 1, p. 63-74, 2011. DOI: $10.5216 /$ bgg.V31i1.15400

BORGES, T.K. de S. Evaporação em superfície de água livre com baixa turbidez. 2017. 133 p. Tese de Doutorado (UFRB - Universidade Federal do Recôncavo da Bahia, Cruz das Almas, BA)

COSTA, G.B.; LYRA, R.F.F. Análise dos padrões de vento no estado de Alagoas. Revista Brasileira de Meteorologia, v. 27, n. 1, p. 31-38, 2012.

DADASER-CELIK, F.; CENGIZ, E. Wind speed trends over Turkey from 1975 to 2006. International Journal of Climatology, v. 34, p. 1913-1927, 2014. DOI: 10.1002/joc.3810.

D' ANGiolella, G.; Rebello, E.; ANUNCIAÇÃO, Y. \& BALEeIRO, C. Influência dos fenômenos acoplados oceano-atmosfera na precipitação de Cruz das Almas, Bahia. Bahia Agrícola, v. 5, n. 1, p. 49-52, 2002. 
BORGES, T. K. de S; OLIVEIRA, A. S. de; SILVA, N. D. da

Análise da velocidade e direção do vento em Cruz das Almas, Bahia, no período 1973-2001.

HASSE, L. Beaufort wind scale. Encyclopedia of Atmospheric Sciences, $2^{\text {nd }}$ ed., v. 1, p. 189-195, 2003. DOI: dx.doi.org/10.1016/B978-0-12-382225-3.00466-7

JENSEN, M.E.; ALLEN, R.G. Evaporation, Evapotranspiration, and Irrigation Water Requirements, $2^{\text {nd }}$ ed. ASCE Manuals and Report on Engineering Practice 70, 2016, 744p.

LUTGENS, F. K., TARBUCK, E. J. The Atmosphere: An Introduction to Meteorology. Pearson Education, 12 ed., Boston, USA, 2013, 528p.

MARTINS, F.R.; GUARNIERI, R.A.; PEREIRA, E.B. O aproveitamento da energia eólica. Revista Brasileira de Ensino de Física, v. 30, n. 1, p. 1304, 2008.

MORAIS, G.M. de; SOBRINHO, J.E.; SANTOS, W. de O.; COSTA, D. de O.; SILVA, S.T.A. da; MANIÇOBA, R.M. Caracterização da velocidade e direção do vento em Mossoró/RN. Revista Brasileira de Geografia Física, v. 7, n. 4, p. 746-754, 2014.

MUNHOZ, F. C.; GARCIA, A. Caracterização da velocidade e direção predominante dos ventos para a localidade de Ituverava-SP. Revista Brasileira de Meteorologia, v. 23, p. 30-34, 2008.

OLIVEIRA, A.S.; PEREIRA, F.A.C.; OLIVEIRA, G.X.S.; BORGES, V.P. Evaporação da água de reservatórios: Medição e estimativa por métodos meteorológicos. In: GHEYI, H.R., PAZ, V.P.S., MEDEIROS, S.S., GALVÃO, C.O. Recursos Hídricos em Regiões Semiáridas: estudos e aplicações. INSA, p. 44-73, 2012.

PONTES, A.K. dos S.; DIAS, G.F. de M.; SOUSA, A.M.L. de. Caracterização da velocidade e direção predominante dos ventos no litoral nordeste paraense. Revista Brasileira de Iniciação Científica, v. 5, n. 1, p. 33-42, 2018.

SILVA, J.B.; ZANUSSO, J.F.; SILVEIRA, D.L.M. Estudo da velocidade e direção dos ventos em Pelotas, RS. Revista Brasileira de Agrometeorologia, Santa Maria, v.5, n.2, p. 227-235, 1997

SILVA, B.B.; ALVES, J.J.A.; CAVALCANTI, E.P.; DANTAS, R.T. Potencial eólico na direção predominante do vento no Nordeste brasileiro. Revista Brasileira de Engenharia Agrícola e Ambiental, v. 6, p. 431 439, 2002.

STULL, R. Practical Meteorology: An Algebra-based Survey of Atmospheric Science. 2017. 944p., Version 1.02b. Disponível em: www.eoas.ubc.ca/books/Practical_Meteorology/ 
BORGES, T. K. de S; OLIVEIRA, A. S. de; SILVA, N. D. da

Análise da velocidade e direção do vento em Cruz das Almas, Bahia, no período 1973-2001.

TORRALBA, V.; DOBLAS-REYES, F.J.; GONZALEZ-REVIRIEGO, N. Uncertainty in recent near-surface wind speed trends: global reanalysis intercomparison. Environmental Research Letters. DOI: $10.1088 / 1748-9326 / a a 8 a 58$

VAREJÃO-SILVA, M.A. Meteorologia e Climatologia. Brasília, INMET, 2001. 532p.

WMO - World Meteorological Organization (WMO-No. 8). Guide to Meteorological Instruments and Methods of Observation: Geneva, Switzerland, 2008. 681 p. 